\title{
ANALYSIS OF THE LEVEL OF ATTENTION AND MEDITATION IN CHILDREN, IN THE DEVELOPMENT OF ONLINE CLASSES CAUSED BY THE COVID-19, THROUGH A BRAIN-COMPUTER INTERFACE
}

\author{
WILVER AUCCAHUASI ${ }^{1}$, CHRISTIAN OVALLE ${ }^{1}$, EDWARD FLORES ${ }^{1}$, FERNANDO SERNAQUÉ ${ }^{2}$, \\ MAX HUARANJA ${ }^{2}$, KARIN ROJAS ${ }^{3}$, EDWIN FELIX ${ }^{3}$, MARIO RUIZ ${ }^{3}$, OSCAR LINARES ${ }^{4}$, GLORIA \\ ROJAS $^{5}$ \\ ${ }^{1}$ Universidad Privada del Norte, Lima, Perú \\ ${ }^{2}$ Universidad Nacional Federico Villarreal, Lima, Perú \\ ${ }^{3}$ Instituto Peruano de Investigación en Ingeniería Avanzada, Lima, Perú \\ ${ }^{4}$ Universidad Cesar Vallejo, Lima, Perú \\ ${ }^{5}$ Servicio Nacional de Aprendizaje SENA- Region Caldas, Manizales, Colombia
}

\begin{abstract}
Online classes have become in these times of pandemic by COVID-19, an alternative to continue studying; applied at all educational levels, from schoolchildren to postgraduate studies through University and Technical studies. This study evaluates the levels of attention and meditation applied to children from 8 to 12 years old, when they are doing their virtual classes, using a BCI device, which is installed on the children's head like a headband. Through which the level of attention and meditation is evaluated at the time of taking their classes online. The results show that children when they start their classes have a higher level of concentration compared to when the class is in the middle where children begin to decrease their level of concentration due to distraction, thus increasing their level of meditation. It is concluded that children tend to be distracted when they reach, on average, half the assigned time, this decrease in the concentration level caused by distracting agents, who are at home. Product of the little conditioning that the homes present to carry out academic activities, it is recommended at the time of the virtual classes, it is possible to eliminate, as far as possible these distracting agents, to improve the level of attention and with it a better use of the classes online, it is also recommended that a home environment for these activities be conditioned as much as possible, although being confined at home causes a change in study habits, they must adapt to new ways and one of these is the development of activities that correspond to online classes.
\end{abstract}

KEYWORDS: Interface, Meditation, Concentration, Online Classes

Received: Jun 08, 2020; Accepted: Jun 28, 2020; Published: Sep 14, 2020; Paper Id.: IJMPERDJUN20201222

\section{INTRODUCTION}

Educational activities are changing considerably with the progressive use of information and communication technologies, and are being influenced to a greater degree at times when we are being affected by the pandemic caused by COVID-19. Students are doing their school activities from home, through mobile devices, personal computers, among other mechanisms that can be used for this purpose. By attending their classes from home, they are exposed to various factors that can cause students to be distracted, causing them to be unable to take full advantage of their online class. The use of the brain-computer interface is being used more frequently to measure certain behaviors of the brain in people, that is why we have works where the activities of the brain are measured 
when activities related to video games are being carried out, where it is measured attention span in children [1]. In the area of video games there are many approaches we can take advantage of the use of BCI to find different problems and difficulties. Being able to design, extend and take advantage of games with devices that can measure brain activity [2]. We also find works where developments based on the use of the BCI for IT learning are presented, these are currently used in people with motor disabilities, where they cannot access the learning of Information Technologies in Educational Institutions, because it does not have the appropriate tools to impart this type of education. [3]. In the educational area we find studies that measure the signs of degrees of stress and centralism received from the stimuli in the mathematical and humanities areas applied to a group of children with one who is between six and seven years of age, where used as a BCI device as a Neurosky interface and the development of a software application created with $\mathrm{C}++$ in the Qt Creator improvement environment, through which we can expand our knowledge of $\mathrm{BCI}$, from which it can be said that this interface has been using electrical activity of the brain as a signal that represents the messages or commands that a person sends to the outside world [4]. In the analysis of the behavior of the brain we found works where the EEG electroencephalography signals are measured, presenting the parameters of voltage and periodicity through a web application in real time and the application of the OpenBCI hardware. These signals were pre-processed in Matlab and by examining FP1 and FP2 a foreign connector was controlled by means of the voluntary wink. Also, the method allows the recipient to pay attention to the behavior of the brain waves and the evoked potentials produced during the examination [5].

\section{METHODS \& MATERIALS}

The methodology presented is the use of a BCI device, whose function is to measure and record the signals produced by the brain and interpret them, providing the level of concentration and the level of meditation that you are presenting at the time of signal log. The components of the methodology are presented below:

\section{BLOCKS DIAGRAM}

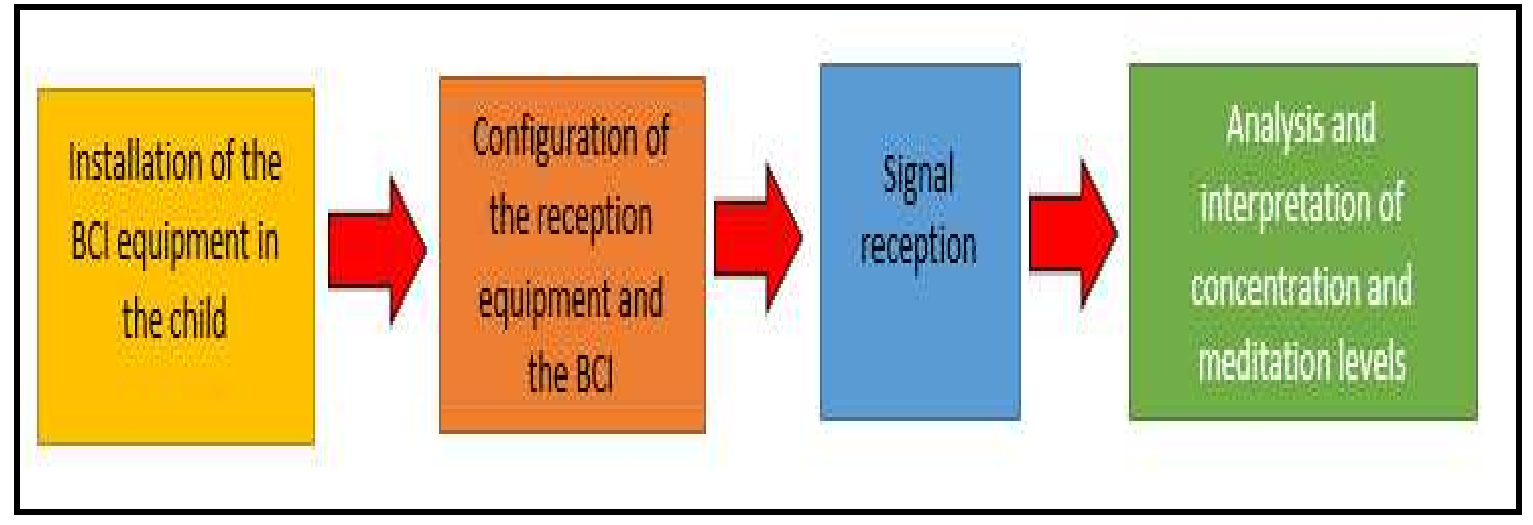

Figure 1: Block Diagram of the Proposal.

The first block corresponds to the installation of the $\mathrm{BCI}$ device in the child, the device is a vicha that is placed at the height of the foreheads, allowing the child to carry out his activities normally, the correct location of the equipment in the child, will have as a result, the signal capture is as clean as possible, causing a better interpretation.

The second block corresponds to the configuration of the reception equipment with the $\mathrm{BCI}$ device, this configuration must be carried out with all possible security, so that the signal can be registered without noise, because the 

caused by the Covid-19, through a Brain-Computer Interface

communication of the equipment with the BCI device It is wireless. The configuration of the communication protocol will allow the signal to reach the receiving equipment with the highest possible fidelity.

The third block corresponds to the signal reception block, which corresponds to the reception equipment and is where it receives the signal and processes them to indicate the concentration and meditation levels of the person under study.

The fourth final block corresponds to the analysis and interpretation of the concentration and meditation levels, carried out in the conditions when the child is in her online classes. The analysis mechanism is the recording of brain signals at different times when taking classes and taking an average value for their interpretation.

The measurements were made taking as a model different environments where they have been designated in the houses or apartments, to be able to carry out the virtual classes. The concentration levels measured by the BCI device is characterized by the presentation on a scale from 1 to 100 , the level of attention that corresponds when the person to be evaluated is paying the most attention to the activity they are performing; The level of meditation is characterized by a scale from 1 to 100 , where the level of meditation corresponds to the moment when the person being evaluated is distracted without paying much attention to the activity they are doing.

\section{RESULTS}

The results presented are related to the experimentation carried out on a group of children between the ages of 8 and 12, who are currently receiving online classes from home, where the BCI device was used to measure the degree of concentration and meditation when they are doing the activities of the class, the time interval where the measurement was made is related to three fundamental times in the development of an online class, looking from the student's perspective:

- When the student prepares to enter the virtual campus.

- When the student starts the class

- When the student is in the first 10 to 15 minutes of class

- When the student is in the middle of the class

Although the classrooms of the schools are conditioned so that the child develops all his abilities, through conditioning, the educational resources available, adequate lighting, among others, make it possible for him to be paying attention to the teacher's class, this This characteristic changes dramatically when the child is attending his classes where the teacher is online, where he can only have interaction through audio or video camera, and added to the distracting agents that we find in the living room of the house, which is the place where in most cases he conditioned himself to receive classes online, among the distracting agents we can mention the television, toys, brothers. It should be noted that for this reason the living room of the house is not an appropriate place to carry out academic activities in children who are in training.

Below are the results obtained in the average measurements of children in these four essential moments in the development of online classes: 

Max Huaranja, Karin Rojas, Edwin Felix, Mario Ruiz, Oscar Linares, Gloria Rojas

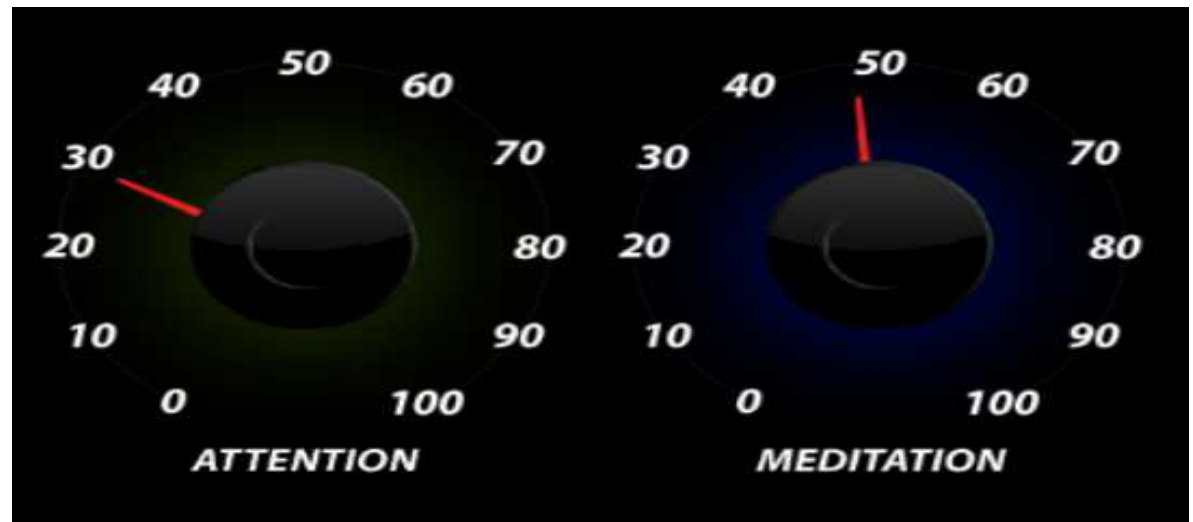

Figure 2: Attention and Meditation Level when the Child is Getting Ready to Start her Online Class.

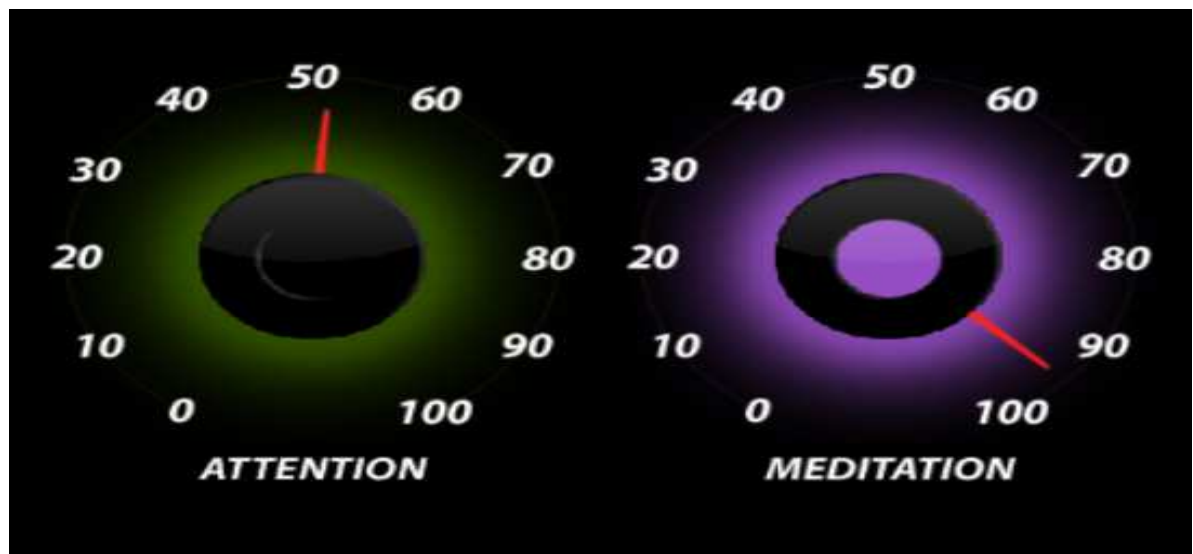

Figure 3: Level of Attention and Meditation when the Child Started his Online Class.

In Figure 2, the concentration and meditation levels are presented, when the child is preparing to enter his online class, it can be seen that his concentration is at a level of 30 and the meditation level is at 49 , indicating that the child is distracted without any concern at that time.

Figure 3 shows the levels of attention with a value of 52 and meditation at 95, these data indicate that the child is starting his online classes, the child is still distracted but begins to pay attention to the class.

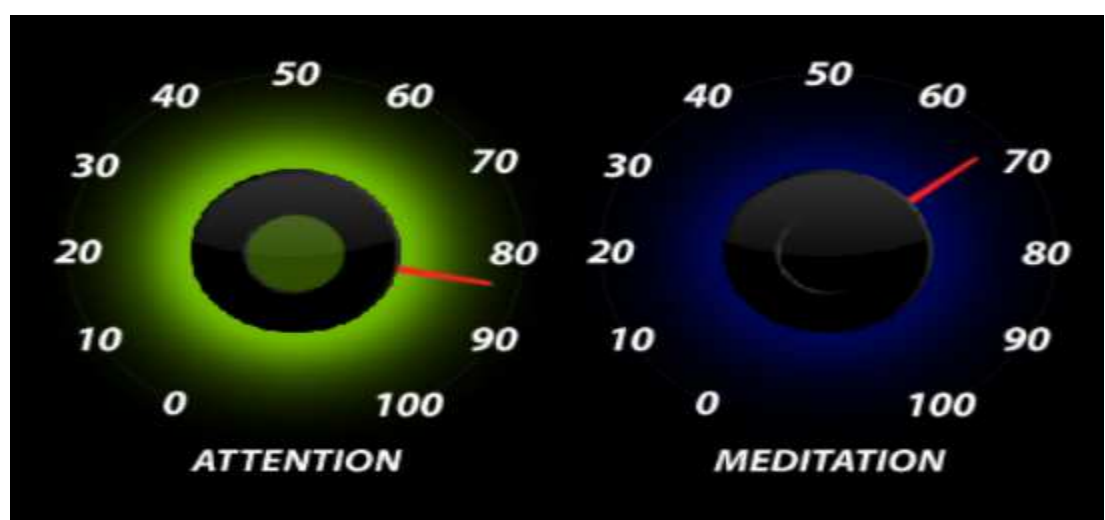

Figure 4: Level of Attention and Meditation when the Child is in the First 10 to 15 Minutes of her Online Class. 
In figure 4, the maximum peak of the concentration level is presented with a value of 84 , which indicates that the child is highly concentrated in the activities of the online class, but also presents a value of 67 in the level of meditation what indicating that although you are paying attention to the online class, you are somewhat distracted, it would be expected at this point in the class, that the value of attention is as high as possible and the value of meditation is as low as possible.

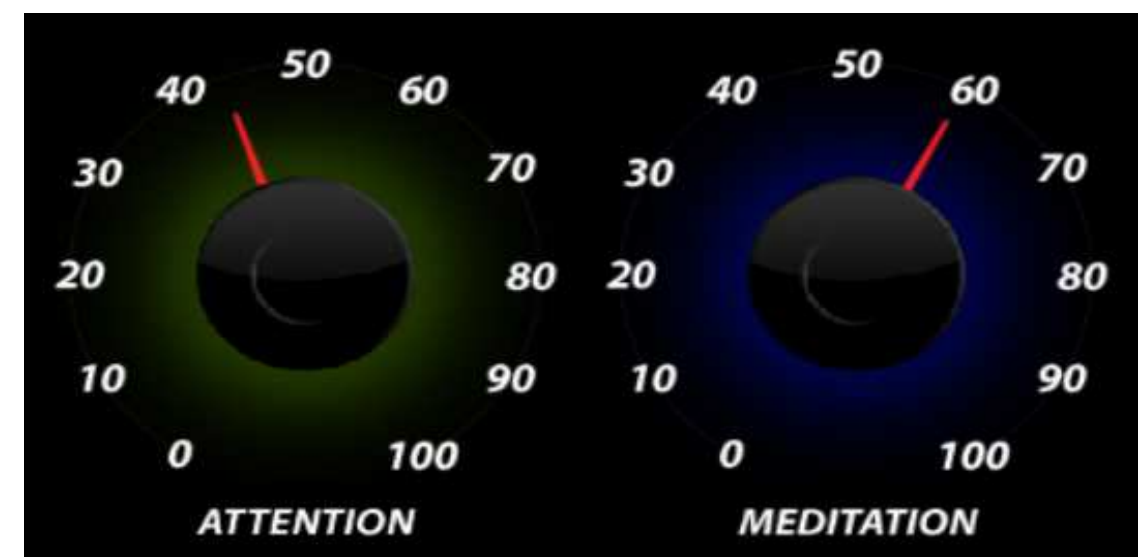

Figure 5: Attention and Meditation Level when the Child is in the Middle of his Online Class.

Figure 5 presents the results when the child is in the middle of the virtual class hours, on average after 20 minutes, of a class scheduled in 40 minutes, as it can be seen after about 20 minutes, the children begin to Losing attention to the online class caused by different factors, such as visual fatigue, discomfort, inappropriate environments and distracting agents such as television, toys, among others.

\section{CONCLUSIONS}

The results presented show that virtual classes have an important application in the development of education in children in these times of quarantine, the measurements made show that the levels of attention are presented with higher levels in the first minutes of the online class., which is the moment where children have the greatest interest in being attentive to classes, if we make a comparison with the work presented by the author which is indicated in the first reference where levels of attention and meditation are measured when children They are playing video games, where children have high levels of attention with a main characteristic that these levels are maintained for a long time, depending on the duration of the game, on average $80 \%$ of the duration of the game, for this reason it is important to achieve develop recreational activities in the development of online classes with the intention that children can take advantage of interest in video games, applying to learning processes.

In the development of this project, it was verified that online classes are producing changes in the development of children's study habits, being able to develop classes from home is one of the challenges that all families assume, by being able to condition the environments of the houses to be able to develop the online classes. There is a substantial difference between the facilities of a classroom and the environments of the houses, due to its fundamental use, it is for this main reason that distractors, such as toys, are present at home the room or children's rooms, these make it easier for children to be distracted compared to school environments. We can also indicate that in a normal session of online classes, the first 10 to 15 minutes the children present a high level of attention, which indicates that they are paying attention to the classes, 
after 20 minutes of a class scheduled in 40 minutes, children lose that first attention causing distractions, we can conclude that you should take advantage of these first minutes in order to present the most important knowledge, it is also recommended that online classes not only be able to observe the screens, interactive activities should be implemented which causes the children to be the majority of the class with the interest of participating and getting the most out of the classes.

\section{REFERENCES}

1. Wilver Auccahuasi, Mónica Díaz, Fernando Sernaque, Edward Flores, Gabriel Aiquipa, Gloria Rojas, Percy Castro, and Nabilt Moggiano. 2019. Analysis of the comparison of the levels of concentration and meditation in the realization of academic activities and activities related to videogames, based on brain computer interface. In Proceedings of the 5th International Conference on Communication and Information Processing (ICCIP '19). Association for Computing Machinery, New York, NY, USA, 154-157.

2. DOI:https://doi.org/10.1145/3369985.3370017

3. Dávila, J. A. V., Macías, J. V., \& Lamas, M. V. (2017). Videojuegos basados en BCI (Interface cerebro computadora): Revisión Sistemática Literaria. Programación Matemática y Software, 9(2), 10-23

4. VALENCIA-GARCÍA, A., JUAREZ-SANTIAGO, B., CORTÉS-GARCÍA, A., \& VELAZQUEZ-GACHUZO, E. (2016). Estudio del estado del arte para el desarrollo de un motor gráfico que utilice Interfaz Cerebro-Computadora (BCI) para el aprendizaje de las TI. Revista de Sistemas Computacionales y TIC's, 5.

5. RODRÍGUEZ-MIRANDA, G., SANTOS-OSORIO, R., LEDESMA-URIBE, N., \& CAMACHO-RAMÍREZ, J. (2016). Estudio de las señales electroencefalográficas (EEG) desarrollando una aplicación basada en interfaz cerebro-computadora (BCI), para el apoyo del aprendizaje infantil. Revista de Sistemas Computacionales y TIC's, 2(6), 1-4.

6. Vásquez Rodríguez, G. J., \& Urgilés Cárdenas, D. F. (2017). Implementación de un Sistema BCI para el Análisis del Comportamiento de Bioseñales Neurológicas (Bachelor's thesis, Universidad del Azuay). 